\title{
NIRS Characterization of Paper Pulps to Predict Kappa Number
}

\author{
Ana Moral, ${ }^{1}$ Elena Cabeza, ${ }^{1}$ Roberto Aguado, ${ }^{2}$ and Antonio Tijero ${ }^{2}$ \\ ${ }^{1}$ Chemical Engineering Department, Experimental Sciences Faculty, Pablo de Olavide University, Road of Utrera $\mathrm{km} 1$, \\ 41013 Seville, Spain \\ ${ }^{2}$ Grupo de Celulosa y Papel, Chemical Engineering Department, Faculty of Chemistry, Complutense University of Madrid, \\ Avenue Complutense s/n, 28040 Madrid, Spain \\ Correspondence should be addressed to Ana Moral; amoram@upo.es
}

Received 8 August 2014; Revised 18 October 2014; Accepted 27 October 2014

Academic Editor: Ming-Guo Ma

Copyright (c) 2015 Ana Moral et al. This is an open access article distributed under the Creative Commons Attribution License, which permits unrestricted use, distribution, and reproduction in any medium, provided the original work is properly cited.

Rice is one of the most abundant food crops in the world and its straw stands as an important source of fibres both from an economic and an environmental point of view. Pulp characterization is of special relevance in works involving alternative raw materials, since pulp properties are closely linked to the quality of the final product. One of the analytical techniques that can be used in pulp characterization is near-infrared spectroscopy (NIRS). The use of NIRS has economic and technical advantages over conventional techniques. This paper aims to discuss the convenience of using NIRS to predict Kappa number in rice straw pulps produced under different conditions. We found that the resulting Kappa number can be acceptably estimated by NIRS, as the errors obtained with that method are similar to those found for other techniques.

\section{Introduction}

The use of wood as the main raw material in the pulp and paper industry is related to some economic and environmental issues. Wood prices make up the largest part of the costs of cellulose pulp production. While most of the wood comes from plantation forests, this has raised some controversy due to some natural forests having been replaced by monocultures. These are two of the reasons that have fostered research into the use of alternative, nonwood raw materials in response to environmental and economic pressure. In fact, nonwood raw materials constitute the sole effective source of cellulose fibre in some regions of the world where wood is a scarce resource [1-4].

Rice for human consumption belongs commonly to species Oryza sativa or Oryza glaberrima; the latter, however, is much less widely used than the former and its production is restricted to West Africa [5]. Rice straw is an abundant nonwood raw material due to the large disposal of it which takes place during the harvest which poses serious problems to farmers. Traditionally, straw has been burnt on site. This practice generates heavy smoke frequently resulting in breathing, cardiorespiratory, and allergic problems in nearby populations and also in the release of large amounts of carbon dioxide to the environment. However, rice straw can be processed differently in order to facilitate its valorisation. One way is by using it as animal feed; however, advocates and detractors of this use disagree on the actual protein value and the digestibility of the material [6]. Another way is by using straw ash or husk ash, which is similar in composition, to extract silicon [7]. This substance can also be obtained from the liquors of alkaline and acid treatments [8]. In any case, using rice straw to produce cellulose pulp [9] is the most attractive choice.

The growing concern with the preservation of the environment in developed societies must be reconciled with the increasing demand for paper and board pulp worldwide. This leads to a new focus on the use of alternative raw materials and the development of pulping processes which cause less environmental impact (soda, soda-anthraquinone) [10].

Pulps characterization has special relevance in studies related to the use of alternative raw materials through less polluting processes in the pulp and paper industry. Pulp properties are closely linked to the quality of the final product. 
However, conventional techniques imply a high consumption of reagents and time for its realization. At the same time, the destruction of samples during the process hinders the execution of subsequent determinations that could favour the knowledge of other parameters of special interest [11].

From the 1950s, near-infrared spectroscopy (NIRS) began to get known, and its possibilities were foreseen. Previously, only MIR and FIR spectroscopy were considered useful, since they allowed for analysing individual components present in each sample [12]. NIRS began to be used in the characterization of organic compounds from the 60 s and its use has been extended to the control of almost all processes in food, pharmaceuticals, textile, chemical, petrochemical, and medical industries $[13,14]$.

NIRS has a number of advantages over conventional techniques: it suits solids, liquids, and gases and does not require sample pretreatment; the spectral recording and analysis of routine are fast; it is nondestructive and allows for multicomponent analysis and in-line analysis, and it is inexpensive [15].

NIRS is a powerful and fast tool for the determination of the constituents of wood $[16,17]$. There are precedents for the use of the near-infrared spectroscopy for the determination of yield [18] and Kappa number of pulps from hardwoods and softwoods $[19,20]$. Absorption bands observed in the reflectance of the wood spectra arise from the emission of electromagnetic waves produced by the overtones and combinations of $\mathrm{C}-\mathrm{H}, \mathrm{C}-\mathrm{O}, \mathrm{N}-\mathrm{H}$, and $\mathrm{O}-\mathrm{H}$ [18].

The difficulty of NIRS application lies in the nature of spectra combined with the existence of multiple peaks which overlap. Therefore, it is necessary to develop advanced chemometric techniques helping to decipher the wide range of information provided by the spectra. Instruments and software developments have allowed great advances in the applicability of the technique [21].

Multivariate calibration can be difficult to perform, and it generally requires quantitative and qualitative knowledge of the properties of the samples to be analysed. In order to extract valuable information, different chemometric techniques can be used: principal components analysis (PCA), partial least squares (PLS), and multivariate resolution of curves (MCR), to name a few.

In the pulp and paper industry, the determination of the Kappa number is a parameter of special significance, since it is an indirect method to estimate the content of residual lignin and an indicator of bleachability [22]. The aim of this study is to evaluate the potential of NIR technology as a substitute for conventional trials in the determination of the Kappa number. The influence of the variables involved in the cooking process of rice straw on Kappa number has been studied, and so has their relationship with the NIR spectra obtained.

\section{Materials and Methods}

2.1. Raw Material. The rice species used in this study are Oryza sativa (Asiatic) and Oryza glaberrima (African). Rice from both species was grown in the Southeast of Spain and its straw was harvested.
2.2. Pulping. Pulps were obtained by cooking rice straw in a $15 \mathrm{~L}$ batch cylindrical reactor that was heated by means of electrical resistances. Rice straw was placed in the reactor together with soda and anthraquinone and pulped by using a reagent concentration, temperature, cooking time, and a liquid/solid ratio as shown in Table 1 . The operating conditions have been chosen based on previous works [2]. The reactor was linked through an axle to a control unit, which included a motor actuating the reactor and instruments for measurement and control of pressure and temperature. Afterwards, the cooked material was unloaded into a washer in order to remove residual cooking liquor and then fiberized in a disintegrator at $1200 \mathrm{rpm}$ for $30 \mathrm{~min}$. The washed pulp was beaten in a Sprout-Bauer refiner and the fiberized material passed through a screen of $0.16 \mathrm{~mm}$ mesh size in order to remove uncooked particles.

2.3. Experimental Design. Pulping processes have been modelled in various ways for the estimation of Kappa number in terms of process variables, in order to optimize the operating conditions accordingly.

Most of the existing models are kinetic equations. However, to the best of our knowledge, few researchers have used a factorial design that allows for the development of empirical models with several independent variables, to examine the Kappa number. These empirical models are preferable to the mechanistic ones, since the latter are too complex when they contain more than two independent variables.

In this work, we chose a factorial design consisting of a series of points (tests) around a central composition point (central test).

The total number of tests required for the five independent variables studied (namely, temperature $(T)$, time $(t)$, soda concentration $(S)$, anthraquinone concentration $(A)$, and liquid/solid ratio $(H)$ ) was found to be 27 .

The values of the independent variables were normalized:

$$
X_{n}=2 \frac{X-\bar{X}}{X_{\max }-X_{\min }},
$$

where $X_{n}$ is the normalized value of temperature $(T)$, time $(t)$, or liquid/solid ratio $(S) ; X$ is the absolute experimental value of the variable concerned; $\bar{X}$ is the mean of the extreme values of $X$, and $X_{\max }$ and $X_{\min }$ are its maximum and minimum value, respectively. Experimental conditions and normalized values are shown in Table 1.

The experimental data were fitted to the following second order polynomial model:

$$
Y=a_{0}+\sum_{i=1}^{n} b_{i} X_{n, i}+\sum_{i=1}^{n} c_{i} X_{n, i}{ }^{2}+\sum_{i=1}^{n} b_{i} X_{n, i} X_{n, j},
$$

where $i<j . X_{n}$ represent the normalized values of the process variables (time, temperature, concentration of reagents, etc.). The coefficients $a_{0}, b_{i}, c_{i}$, and $d_{i j}$ are constants to be estimated from the experimental data.

2.4. Determination of Kappa Number. Kappa number was determined in accordance with ISO 302:2004, applicable for 
TABLE 1: Values of operating variables used in the design of experiments.

\begin{tabular}{|c|c|c|c|c|c|c|c|c|c|c|}
\hline Experiment & $T,{ }^{\circ} \mathrm{C}$ & $t, \min$ & Soda, $\%$ & Anthraquinone, \% & Liquid/solid ratio & $X_{T}$ & $X_{t}$ & $X_{S}$ & $X_{A}$ & $\overline{X_{H}}$ \\
\hline 1 & 170 & 60 & 15 & 0.5 & 6 & 0 & 0 & 0 & 0 & 0 \\
\hline 2 & 155 & 30 & 10 & 1 & 4 & -1 & -1 & -1 & 1 & -1 \\
\hline 3 & 155 & 30 & 10 & 0 & 8 & -1 & -1 & -1 & -1 & 1 \\
\hline 4 & 155 & 30 & 20 & 1 & 8 & -1 & -1 & 1 & 1 & 1 \\
\hline 5 & 185 & 60 & 15 & 0.5 & 6 & 1 & 0 & 0 & 0 & 0 \\
\hline 6 & 170 & 60 & 15 & 1 & 6 & 0 & 0 & 0 & 1 & 0 \\
\hline 7 & 170 & 30 & 15 & 0.5 & 6 & 0 & -1 & 0 & 0 & 0 \\
\hline 8 & 170 & 60 & 10 & 0.5 & 6 & 0 & 0 & -1 & 0 & 0 \\
\hline 9 & 185 & 30 & 10 & 1 & 8 & 1 & -1 & -1 & 1 & 1 \\
\hline 10 & 185 & 30 & 20 & 1 & 4 & 1 & -1 & 1 & 1 & -1 \\
\hline 11 & 170 & 60 & 20 & 0.5 & 6 & 0 & 0 & 1 & 0 & 0 \\
\hline 12 & 170 & 90 & 15 & 0.5 & 6 & 0 & 1 & 0 & 0 & 0 \\
\hline 13 & 185 & 30 & 20 & 0 & 8 & 1 & -1 & 1 & -1 & 1 \\
\hline 14 & 170 & 60 & 15 & 0.5 & 8 & 0 & 0 & 0 & 0 & 1 \\
\hline 15 & 155 & 60 & 15 & 0.5 & 6 & -1 & 0 & 0 & 0 & 0 \\
\hline 16 & 185 & 90 & 10 & 0 & 8 & 1 & 1 & -1 & -1 & 1 \\
\hline 17 & 170 & 60 & 15 & 0 & 6 & 0 & 0 & 0 & -1 & 0 \\
\hline 18 & 155 & 90 & 20 & 0 & 8 & -1 & 1 & 1 & -1 & 1 \\
\hline 19 & 185 & 90 & 20 & 0 & 4 & 1 & 1 & 1 & -1 & -1 \\
\hline 20 & 155 & 90 & 20 & 1 & 4 & -1 & 1 & 1 & 1 & -1 \\
\hline 21 & 185 & 90 & 20 & 1 & 8 & 1 & 1 & 1 & 1 & 1 \\
\hline 22 & 155 & 90 & 10 & 1 & 8 & -1 & 1 & -1 & 1 & 1 \\
\hline 23 & 185 & 90 & 10 & 1 & 4 & 1 & 1 & -1 & 1 & -1 \\
\hline 24 & 155 & 30 & 20 & 0 & 4 & -1 & -1 & 1 & -1 & -1 \\
\hline 25 & 155 & 90 & 10 & 0 & 4 & -1 & 1 & -1 & -1 & -1 \\
\hline 26 & 170 & 60 & 15 & 0.5 & 4 & 0 & 0 & 0 & 0 & -1 \\
\hline 27 & 185 & 30 & 10 & 0 & 4 & 1 & -1 & -1 & -1 & -1 \\
\hline
\end{tabular}

$X_{T}, X_{t}, X_{S}, X_{A}$, and $X_{H}=$ normalized values of temperature $(T)$, time $(t)$, soda concentration $(S)$, anthraquinone concentration $(A)$, and liquid/solid ratio $(H)$, respectively.

a wide range of values, from 1 to 100 . It aims to determine the degree of delignification of pulp. It is defined as the volume (in $\mathrm{mL}$ ) of a $0.1 \mathrm{~N}$ solution of potassium permanganate that is consumed per gram of dry pulp. Iodometric titration was performed to measure permanganate consumption. Three repetitions were made for each test.

2.5. NIR Spectroscopy Analysis. All samples were scanned by duplicate with a Foss NIRSystems 6500 monochromator (Foss NIRSystems, Silver Spring, MD, USA) using the WinISI II 1.5 software (Infrasoft International, Port Matilda, PA, USA). This software was also used for the treatment of the spectral data obtained. The visible and NIR (VNIR) spectra (400 to $2500 \mathrm{~nm}$ ) were collected at $2 \mathrm{~nm}$ intervals. Samples were placed in a rectangular cell with a $4.5 \times 5.5 \mathrm{~cm}^{2}$ quartz window.

2.6. Spectral Data Analysis. Spectral data analysis and calibration equations were performed with WinISI II 1.5 software (Infrasoft International, Port Matilda, PA, USA). Data of calibration sets were subjected to spectral pretreatments combined with mathematical pretreatments. Standard normal variate (SNV) and Multiplicative scatter correction (MSC) were used as spectral pretreatments [23].

SNV is often used on spectra where baseline and path length changes cause differences between otherwise identical spectra. Mathematically, it is identical to an autoscaling of the rows instead of the columns of the matrix.

Multiplicative scatter correction (MSC) is achieved by regressing a measured spectrum against a reference spectrum and then correcting the measured spectrum using the slope and intercept of this linear fit. This pretreatment method has proven to be effective in minimizing baseline offsets and multiplicative effect.

As for mathematical pretreatments, first and second derivatives were used to reduce baseline variation and enhance spectral features. Two preprocessing methods were evaluated: $(1,4,4,1)$ and $(2,5,5,1)$. The numbers in parentheses, respectively, designate the order of the derivative, the gap, the first smoothing, and the second smoothing [24].

Calibration in all cases was based on full cross-validation. Modified partial least square regression (MPLSR) [22] was used to relate spectra with the measured values of dependent variables. Multivariate regression was carried out using the partial least squares (PLS) algorithm. 
The residuals obtained after the calculation of each regression term in the modified partial least squares (MPLS) regression were standardized dividing by the standard deviation before the calculation of the next regression term. According to Shenk and Westerhaus [25], the number of terms was fixed when the SECV presented a minimum value before overfitting.

The different pretreatments were characterised by calculating the standard error of cross-validation (SECV) and the coefficient of determination of cross-validation (1-VR). Two measurements of each sample were used to estimate the standard error of the reference method (ETL):

$$
\mathrm{ETL}=\sqrt{\frac{\sum\left(y_{1}-y_{2}\right)}{2 N}}
$$

where $y_{1}$ and $y_{2}$ are the values obtained for a sample and its repetition and $N$ is the number of data pairs used to calculate the ETL.

\section{Results and Discussion}

Table 2 gives the results of the tests (Kappa number) as the averages of three determinations for each set of independent variables. Relative standard deviation was never higher than $5 \%$.

We dealt with experimental data by using nonlinear regression to fit them to a polynomial model of second degree described in the experimental part (see (2)). This regression analysis is conducted considering five independent variables, these same variables to the square and its products two to two, thus neglecting higher order terms.

The statistically significant terms of the polynomial model were selected with the double standard of having a value of Snedecor's $F$ greater than 4 and a Student's $t$ greater than 2.0. Also, coefficients whose $95 \%$ confidence interval included 0 were discarded.

We found the following equation:

$$
K N=10.9+1.7 X_{A} X_{H}-2.0 X_{t}-2.2 X_{S}-2.6 X_{T} .
$$

As expected, time, soda concentration, and temperature were found to be the most influencing independent variables. Equation (4) also shows that there is a significant interaction between anthraquinone concentration and the liquor-tosolid ratio.

Statistical parameters of the model are shown in Table 3. This model provides a good fit of the experimental data to the polynomial model, as indicated by the values of $R$-multiple, $R^{2}, R^{2}$-adjusted, Student's $t$ (given for a 95\% confidence level), and Snedecor's $F$ of the terms of (4).

According to the model, the lowest value of Kappa number that can be obtained, as long as the values of independent variables fall into the intervals considered, is 2.40. The values needed to achieve that local optimum are temperature of $185^{\circ} \mathrm{C}$, time of $90 \mathrm{~min}, 20$ grams of soda per 100 grams of dry pulp, 1 gram of anthraquinone per 100 grams of dry pulp, and a liquid-to-solid ratio of 4 . If a brighter pulp with a lower Kappa number is desired, operating under more severe conditions is necessary.
TABLE 2: Kappa number values obtained by iodometric titration for

\begin{tabular}{|c|c|c|c|c|c|}
\hline$X_{T}$ & $X_{t}$ & $X_{S}$ & $X_{A}$ & $X_{H}$ & Kappa number \\
\hline 0 & 0 & 0 & 0 & 0 & 9.4 \\
\hline-1 & -1 & -1 & 1 & -1 & 16.5 \\
\hline-1 & -1 & -1 & -1 & 1 & 16.8 \\
\hline-1 & -1 & 1 & 1 & 1 & 16.0 \\
\hline 1 & 0 & 0 & 0 & 0 & 8.8 \\
\hline 0 & 0 & 0 & 1 & 0 & 9.3 \\
\hline 0 & -1 & 0 & 0 & 0 & 11.6 \\
\hline 0 & 0 & -1 & 0 & 0 & 11.7 \\
\hline 1 & -1 & -1 & 1 & 1 & 14.8 \\
\hline 1 & -1 & 1 & 1 & -1 & 6.7 \\
\hline 0 & 0 & 1 & 0 & 0 & 8.9 \\
\hline 0 & 1 & 0 & 0 & 0 & 9.2 \\
\hline 1 & -1 & 1 & -1 & 1 & 7.1 \\
\hline 0 & 0 & 0 & 0 & 1 & 9.3 \\
\hline-1 & 0 & 0 & 0 & 0 & 14.5 \\
\hline 1 & 1 & -1 & -1 & 1 & 7.8 \\
\hline 0 & 0 & 0 & -1 & 0 & 9.5 \\
\hline-1 & 1 & 1 & -1 & 1 & 8.1 \\
\hline 1 & 1 & 1 & -1 & -1 & 6.4 \\
\hline-1 & 1 & 1 & 1 & -1 & 8.0 \\
\hline 1 & 1 & 1 & 1 & 1 & 6.5 \\
\hline-1 & 1 & -1 & 1 & 1 & 15.3 \\
\hline 1 & 1 & -1 & 1 & -1 & 7.2 \\
\hline-1 & -1 & 1 & -1 & -1 & 15.1 \\
\hline-1 & 1 & -1 & -1 & -1 & 16.2 \\
\hline 0 & 0 & 0 & 0 & -1 & 9.4 \\
\hline 1 & -1 & -1 & -1 & -1 & 15.2 \\
\hline
\end{tabular}
the different operating variables of the experimental design.

TABLE 3: Values of statistical parameters for the fitting of experimental data (Kappa number) to (4).

\begin{tabular}{lcccc}
\hline Fitting parameter & $R$-multiple & $R^{2}$ & $R^{2}$-adjusted & $t>$ \\
\hline Value & 0.96 & 0.93 & 0.92 & 6.69 \\
\hline Equation term & $X_{A} X_{H}$ & $X_{t}$ & $X_{S}$ & $X_{T}$ \\
\hline Snedecor's $F$ & 44.71 & 65.48 & 80.23 & 112.55 \\
\hline
\end{tabular}

As can be seen from Figure 1, all spectral data were summarized in a few variables (PLS terms of multivariate regression) with good correlation with reference values. In the graph, the predicted values ( $x$-axis) do not deviate in more than $8 \%$ from the reference values ( $y$-axis).

In order to determine the relevance of the simultaneous analysis of visible and NIR (VNIR) spectroscopy with the aim to perform forecasting based only with NIRS, a set of trials were carried out using both analytic methods. The VNIR trials were carried out in a spectral region between 400 and $2500 \mathrm{~nm}$ and the NIR samples were processed in a spectral region between 1100 and $2500 \mathrm{~nm}$, as Figure 2 shows. Figure 2(a) shows the whole near-infrared spectrum with no mathematical pretreatment, while Figure 2(b) focuses on the 


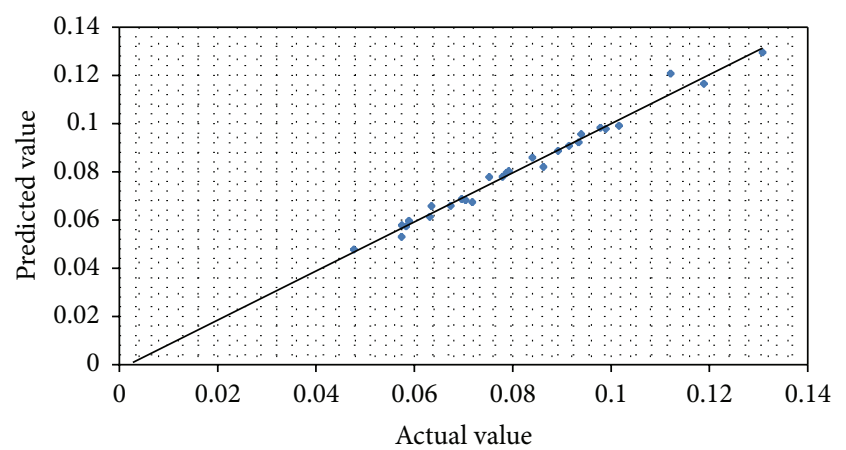

FIgURE 1: Correlation of the PLS terms with spectral data.

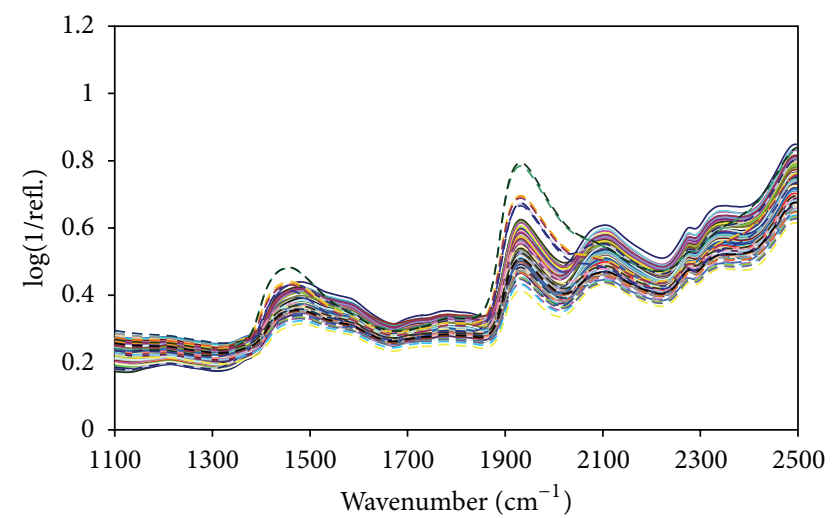

(a)

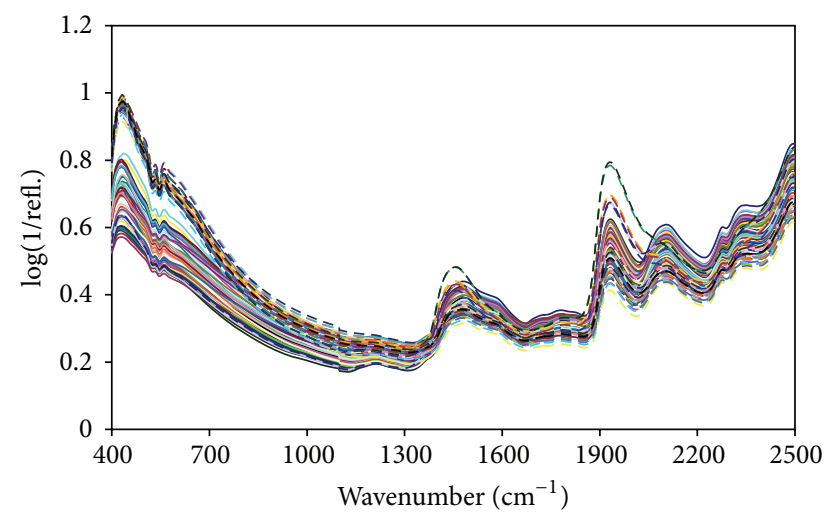

(b)

FIGURE 2: Near-infrared (NIR) and visible NIR (VNIR) spectra for the samples.

visible part. The whole NIR spectrum shows a peak outside of the visible region, at $450 \mathrm{~cm}^{-1}$.

As it is shown in Table 4, the reference error (ETL) used in the calculation of Kappa number was 0.11. The error (as SECV) obtained by the mathematical method $(1,4,4,1)$ in the trials carried out for NIR was lower than that obtained by the mathematical methods $(2,5,5,1)$ for NIR. The coefficients of determination of cross-validation (measurement of the expected explained variation) obtained support the use of the NIR prediction method for the determination of Kappa index
TABLE 4: Comparison between the errors obtained by VNIR, NIR, and the standard error of the reference method (Kappa number).

\begin{tabular}{lcccc}
\hline Treatment & SECV & 1-VR & ETL & CV (\%) \\
\hline $1,4,4,1 \_V N I R$ & 0.13 & 0.92 & & \\
$2,5,5,1 \_V N I R$ & 0.12 & 0.87 & 0,11 & 7,8 \\
$1,4,4,1 \_N I R$ & 0.15 & 0.89 & & \\
$2,5,5,1 \_N I R$ & 0.18 & 0.85 & & \\
\hline
\end{tabular}

present in the raw matter studied. CV (\%), the coefficient of variation, is acceptably low.

These results show that the Kappa number obtained after different cooking processes can be predicted by means of a direct measurement of rice straw pulp, using near-infrared spectroscopy.

\section{Conclusions}

The errors (SECV) obtained in the measurements carried out for VNIR and NIR were similar. The results obtained using a spectral scanning of VNIR and NIR do not show a significant variation between both of the systems used.

The use of NIR technology can be seen as a viable alternative method to predict Kappa number in rice straw pulp subjected to different treatments. The NIR technology also has the additional advantage of being a fast, nondestructive technique that does not need any sample pretreatment. Therefore, the cost and the environmental impact are diminished by removing the chemical reagents needed for other ways to measure Kappa number.

\section{Conflict of Interests}

The authors declare that there is no conflict of interests regarding the publication of this paper.

\section{References}

[1] S. Navaee-Ardeh, J. M. Rovshandeh, A. A. Khodadadi, and M. Pourjoozi, "Pulp and paper characterization of rice straw produced from aqueous ethanol pulping," Cellulose Chemistry and Technology, vol. 37, no. 5-6, pp. 405-413, 2003.

[2] A. Rodríguez, A. Moral, R. Sánchez, A. Requejo, and L. Jiménez, "Influence of variables in the hydrothermal treatment of rice straw on the composition of the resulting fractions," Bioresource Technology, vol. 100, no. 20, pp. 4863-4866, 2009.

[3] H. Roliadi, R. M. Siagian, A. Fauzi Mas'ud, and A. N. Gintings, "The possible utilization of old newsprint, sludge waste, and abaca fibers as raw material for pulp/paper manufacture with satisfactory qualities/results: an attempt to reduce heavy dependency on the conventional wood," in Proceedings of the 57th Appita Annual General Conference and Exhibit, pp. 75-81, May 2003.

[4] L. Jiménez, Pastas celulósicas de materias primas alternativas a las convencionales, Gráficas Sol, Écija, Spain, 2005.

[5] Y. Agnoun, S. S. H. Biaou, M. Sié, R. S. Vodouhè, and A. Ahanchéde, "The African rice Oryza glaberrima Steud: knowledge distribution and prospects," International Journal of Biology, vol. 4, no. 3, pp. 158-180, 2012. 
[6] D. K. Misra, "Pulp and Paper Manufacture Volume 3: Secondary Fibers and Nonwood Pulping," in The Joint Textbook Committee of the Paper Industry, F. Hamilton and B. Leopold, Eds., TAPPI CPPA, Montreal, Canada, 3rd edition, 1993.

[7] M. F. Souza, P. S. Batista, I. Regiani, J. B. L. Liborio, and D. P. F. de Souza, "Rice hull-derived silica: applications in Portland cement and mullize whiskers," Journal of Material Research, vol. 3, no. 2, pp. 25-30, 2000.

[8] H. Q. Lam, Y. L. Bigot, M. Delmas, and G. Avignon, "Formic acid pulping of rice straw," Industrial Crops and Products, vol. 14, no. 1, pp. 65-71, 2001.

[9] M. S. Jahan, Z. Z. Lee, and Y. Jin, "Organic acid pulping of rice straw. II. Bleaching and beating," Cellulose Chemistry and Technology, vol. 39, no. 1-2, pp. 85-94, 2005.

[10] S. Navaee-Ardeh, J. Mohammadi-Rovshandeh, and M. Pourjoozi, "Influence of rice straw cooking conditions in the sodaethanol-water pulping on the mechanical properties of produced paper sheets," Bioresource Technology, vol. 92, no. 1, pp. 65-69, 2004.

[11] A. Van Heiningen, "Converting a kraft pulp mill into an integrated forest biorefinery," Pulp and Paper Canada, vol. 107, no. 6, pp. 38-43, 2006.

[12] T. Davies, "The history of near infrared spectroscopic analysis: past, present and future "from sleeping technique to the morning star of spectroscopy'”' Analusis, vol. 26, no. 4, pp. 17-19, 1998.

[13] W. Abney and E. R. Festing, "On the influence of the atomic grouping in the molecules of organic bodies on their absorption in the infra-red region of the spectrum," Philosophical Transactions of the Royal Society, vol. 172, pp. 887-918, 1881.

[14] L. Zhou, Z. Wu, X. Shi et al., "Rapid discrimination of chlorpheniramine maleate and assessment of its surface content uniformity in a pharmaceutical formulation by NIR-CI coupled with statistical measurement," Journal of Spectroscopy, vol. 2014, Article ID 741246, 9 pages, 2014.

[15] E. N. M. van Sprang, H.-J. Ramaker, J. A. Westerhuis, A. K. Smilde, S. P. Gurden, and D. Wienke, "Near-infrared spectroscopic monitoring of a series of industrial batch processes using a bilinear grey model," Applied Spectroscopy, vol. 57, no. 8, pp. 1007-1019, 2003.

[16] D. B. Easty, S. A. Berben, F. A. DeThomas, and P. J. Brimmer, "Near-infrared spectroscopy for the analysis of wood pulp: quantifying hardwood-softwood mixtures and estimating lignin content," Tappi Journal, vol. 73, pp. 257-261, 1990.

[17] L. Wallbacks, U. Edlund, B. Norden, and T. Iversen, "Multivariate characterization of pulp. Part 1: spectroscopic characterization of physical and chemical differences between pulps using 18C CP/MAS NMR, FT-IR, NIR and multivariate data analysis," Nordic Pulp \& Paper Research Journal, vol. 2, pp. 74-80, 1991.

[18] L. R. Schimleck, P. Payne, and R. H. Wearne, "Determination of important pulp properties of hybrid poplar by near infrared spectroscopy," Wood and Fiber Science, vol. 37, no. 3, pp. 462471, 2005.

[19] A. Terdwongworakul, V. Punsuwan, W. Thanapase, and S. Tsuchikawa, "Rapid assessment of wood chemical properties and pulp yield of Eucalyptus camaldulensis in Thailand tree plantations by near infrared spectroscopy for improving wood selection for high quality pulp," Journal of Wood Science, vol. 51, no. 2, pp. 167-171, 2005.

[20] P. Malkavaara and R. Alén, "A spectroscopic method for determining lignin content of softwood and hardwood kraft pulps," Chemometrics and Intelligent Laboratory Systems, vol. 44, no. 1-2, pp. 287-292, 1998.
[21] A. J. Michell, "Pulpwood quality estimation by near-infrared spectroscopic measurements on eucalypt woods," Appita Journal, vol. 48, pp. 425-428, 1995.

[22] J. S. Shenk and M. O. Westerhaus, "Population definition, sample, selection and calibration procedures for near infrared reflectance," Crop Science, vol. 31, pp. 469-474, 1991.

[23] H. Buddenbaum and M. Steffens, "The effects of spectral pretreatments on chemometric analyses of soil profiles using laboratory imaging spectroscopy," Applied and Environmental Soil Science, vol. 2012, Article ID 274903, 12 pages, 2012.

[24] H. W. Siesler, Y. Ozaki, S. Kawata, and H. M. Heise, Near-Infrared Spectroscopy Principles, Instruments, Applications, WileyVCH, Weinheim, Germany, 2002.

[25] J. S. Shenk and M. O. Westerhaus, "Population structuring of near infrared spectra and modified partial least squares regression," Crop Science, vol. 31, pp. 1548-1555, 1991. 

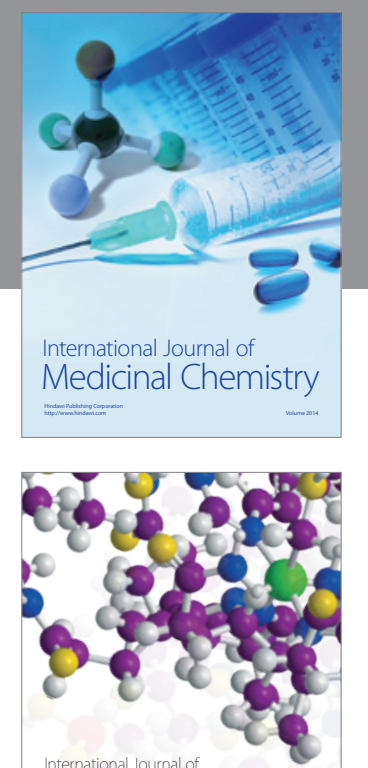

\section{Carbohydrate} Chemistry

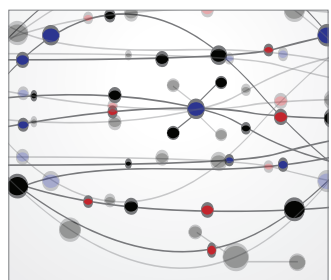

The Scientific World Journal
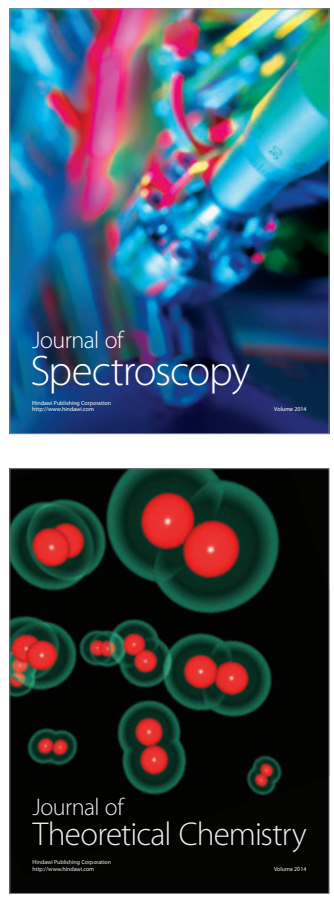
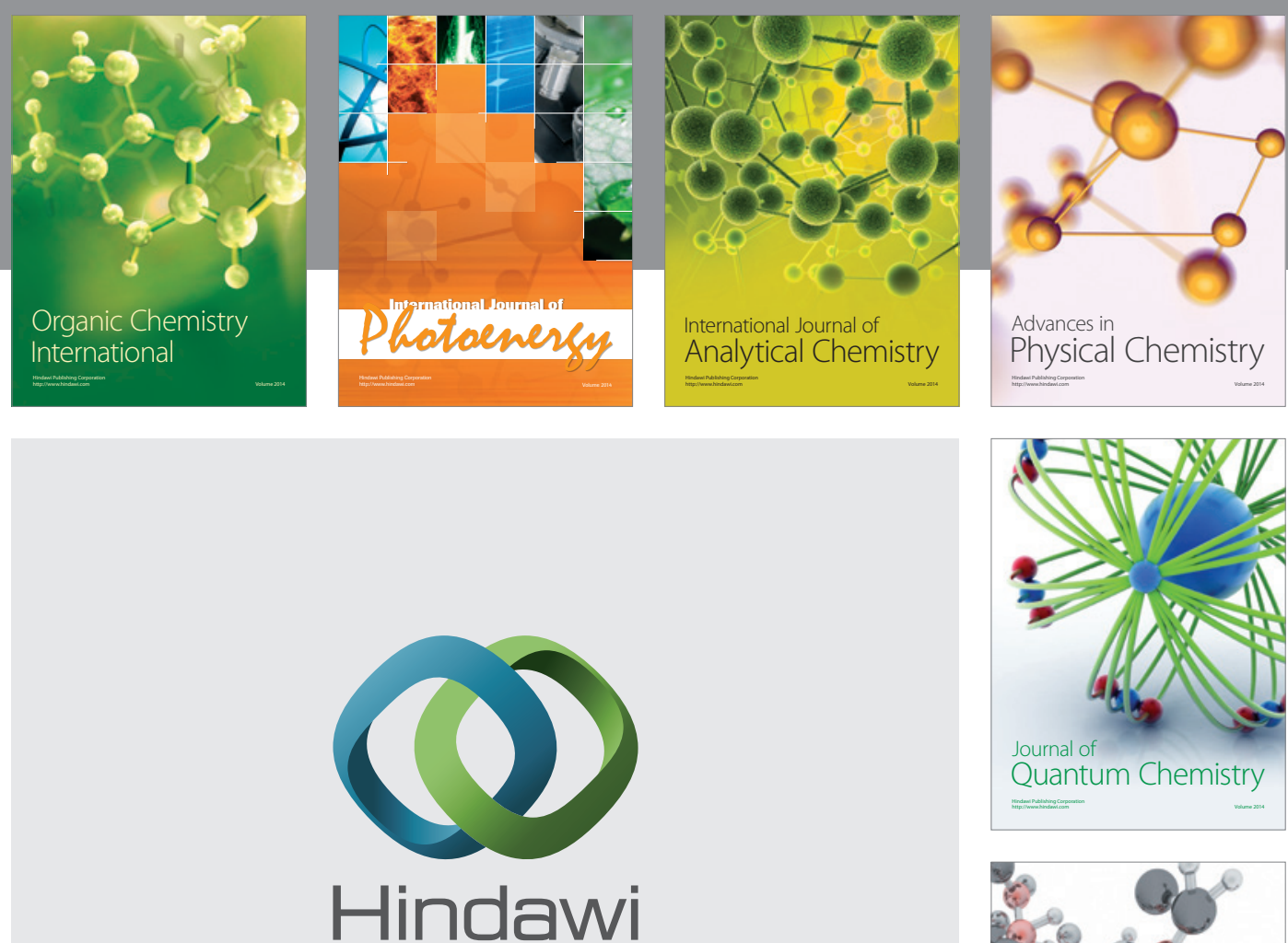

Submit your manuscripts at

http://www.hindawi.com

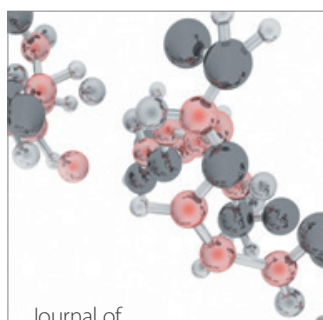

Analytical Methods

in Chemistry

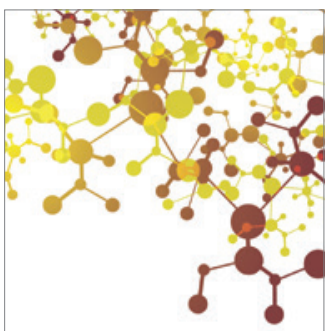

Journal of

Applied Chemistry

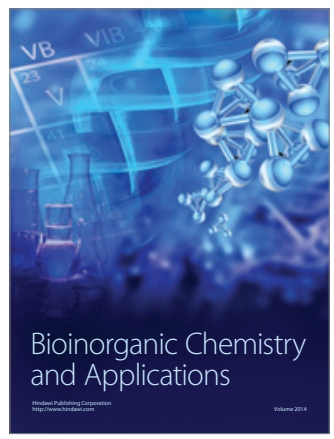

Inorganic Chemistry
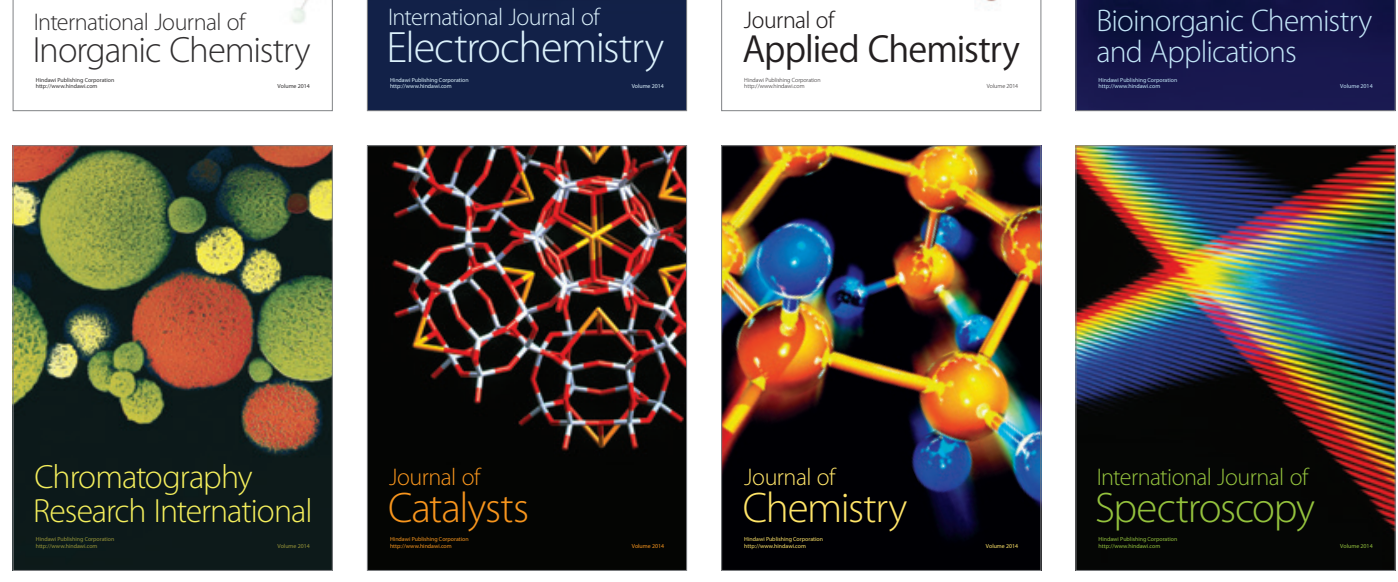